Number of words: 1497

Number of tables: None

Number of references: 28

\title{
Delusional misidentification syndromes in obsessive-compulsive disorder
}

Isabela Melca, M.D., ${ }^{1}$ Clarissa L. Rodrigues, M.D., ${ }^{1}$ Maria A. Serra-Pinheiro, M.D., Ph.D. ${ }^{1}$ Christos Pantelis, M.D., ${ }^{2}$ Dennis Velakoulis, M.D., ${ }^{2}$ Mauro V. Mendlowicz, M.D., PhD., ${ }^{3}$ Leonardo F. Fontenelle, M.D., Ph.D. 1, 3-4

Running head: DMS in OCD

${ }^{1}$ Anxiety and Depression Research Program, Institute of Psychiatry, Federal University of Rio de Janeiro, Brazil; ${ }^{2}$ Melbourne Neuropsychiatry Centre, University of Melbourne, Australia ${ }^{3}$ Department of Psychiatry and Mental Health, Institute of Community Health, Fluminense Federal University, Brazil; ${ }^{4}$ D'Or Institute for Research and Education (IDOR), Rio de Janeiro, Brazil.

Conflict of interest: All authors, with exception of Dr. Serra-Pinheiro, declare that they have no conflict of interest. Dr. Serra-Pinheiro has served as consultant for SIRE and received academic support for medical meetings from SIRE, Eli-lilly, Novartis and Janssen.

Acknowledgements: Prof. Leonardo Fontenelle was supported by grants from

Fundação de Apoio a Pesquisa do Estado do Rio de Janeiro (FAPERJ and Conselho Nacional de Desenvolvimento Científico e Tecnoógico (CNPq). Prof. Christos Pantelis was supported by a National Health and Medical Research Council (NHMRC) Senior Principal Research Fellowship and NHMRC Program Grants.

Corresponding author: Leonardo F. Fontenelle, M.D., Ph.D. Rua Visconde de Pirajá, 547, Sala 719, Ipanema, Rio de Janeiro, CEP: 22410-003, Tel and Fax: +5521-2239-4919, E-mail: lfontenelle@gmail.com

Key words: Obsessive-Compulsive Disorder; Delusions; Capgras Syndrome; Psychopathology 


\section{Abstract}

Delusional misidentification syndromes (DMS) have been rarely reported in patients with conditions other than schizophrenia-related disorders, diffuse brain disease (dementia) and focal neurological illness. In this report, we describe DMS (i.e. Capgras and Fregoli syndromes) in two patients with severe and treatment resistant obsessive-compulsive disorder (OCD), one with paranoid personality disorder (PPD) and the other with a pervasive developmental disorder (PDD) not otherwise specified. While our findings highlight an interesting phenomenon (the occurrence of DMS in OCD), it is presently unclear whether this association is rare or relatively common but underreported. Misidentification syndromes might be the ultimate result of a combination of obsessive fears and preexisting cognitive bias/deficits, such as mistrustfulness (in PPD) or poor theory of mind (in PDD). 


\section{INTRODUCTION}

Patients with obsessive-compulsive disorder (OCD) have been classically described as displaying a high level of insight in relation to their own obsessions or compulsions. However, there is a growing recognition that a significant proportion of patients with OCD may be partially or totally unable to recognize their irrationality [1]. In such cases, the symptoms have been best classified as overvalued ideas or delusions, respectively [2]. However, since there is almost no information on the overlap between the content of OCD-related cognitions (e.g. aggressive, sexual, religious, and contamination themes) and psychotic disorders-related delusions (e.g. persecutory, jealous, erotomanic, somatic and grandiose themes), the existence of a continuum between OCD and delusional or psychotic disorders remains elusive.

Delusional misidentification syndromes (DMS) are conditions in which a patient repeatedly misidentifies persons, places, objects, or events [3]. They are relatively rare psychopathologic phenomena, occurring in about $4 \%$ of patients with functional psychosis [4]. The most common form of DMS is Capgras syndrome, i.e. the "hypoidentification" (non-recognition) of familiar persons, who the patient believes have been replaced by "doubles" or imposters $[3,5]$. There are, however, other less common DMS, e.g. the "hyperidentification" (recognition) of well known persons (usually a persecutor) among people in the environment (i.e. Fregoli syndrome), who might also interchange with each other (i.e. Intermetamorphosis), or transform into the patient's self (i.e. syndrome of subjective doubles) [5]. The diagnosis of DMS is more than a mere 
exercise of academic interest, given its association with violent behavior [6, 7] or even homicide [8].

Misidentification syndromes have been rarely reported in patients with primary non-psychotic conditions $[9,10]$. We are only aware of the report of a 35 yearold married woman with lifelong OCD who had incapacitating doubts about whether her husband, her parents, her cat, and even the city that she lived in had been replaced by identical-appearing duplicates [11]. Of note, this patient's OCD was resistant to "antipsychotics, antidepressants, and multiple courses of electroconvulsive therapy", and recurred even after two neurosurgical procedures (i.e. cingulotomies). In the present paper, we aimed at contributing to the literature by describing two additional patients who developed DMS (Capgras and Fregoli syndromes) during the course of severe and treatment resistant OCD.

\section{CASE REPORTS}

Mrs. A, a 20 year-old married secretary with OCD and paranoid personality disorder (PPD), began exhibiting obsessions with aggressive content and repeating rituals at age 10. At that time, she was concerned about her parents' safety and had to touch objects three to seven times to "undo evil". Concurrently, Mrs. A also exhibited motor tics (including echopraxia), which disappeared during adolescence. While a current diagnosis of OCD was confirmed using the Structured Clinical Interview for DSM-IV Axis I disorder (SCID), paranoid personality disorder (PPD) was diagnosed on clinical grounds (e.g. Mrs. A described that people always 
want to deceive her). At age 17, she started to fear that she had asked different men to have sex with her and had been contaminated with HIV and/or hepatitis. When leaving a room, she would pay careful attention to other people's emotional expressions and statements to ensure that no sexual contact had taken place.

Two years after the birth of her only son, Mrs. A started to obsess about his safety. Specifically, she feared having made a "deal" that involved donating him for sexual practices or having him kidnapped after minor arguments with friends, coworkers, or doorkeepers, among others. She started to suspect that someone had substituted her son with an identical clone to bamboozle her. Although she was not 100\% sure most of time, occasionally she felt like "it was real". This would lead her to spend hours daily checking his body for minor scars, so that she could confirm that her baby was actually her son. Her score on the Yale-Brown Obsessive-Compulsive Scale was 38 (minimum-0; maximum-40). Major depressive disorder was present. MRI scan and organic work-up were normal. Although showing an initial response to high dose serotonin reuptake inhibitors (SRI) and cognitive-behavioral therapy, and remaining under treatment on a long-term basis, Mrs. A OCD eventually relapsed. This time, however, her OCD and Capgras syndrome proved to be treatment resistant to different high-dose SRI potentiated with several strategies (including different atypical antipsychotics).

Mr. B, a 30 year-old single men with high school education, OCD and a pervasive developmental disorder (PDD) not otherwise specified, sought treatment for fearing being raped by a gang of sexual abusers. As a kid, he used to have no friends, to walk in circles, to stutter, and to display frequent outbursts of rage 
towards family members. His mother reported that Mr. B started to show symptoms consistent with OCD, i.e. turning light switches off using his elbow, at age 9. While current OCD diagnosis was confirmed using the SCID, PDD was diagnosed on clinical grounds, based on qualitative impairments in social interaction and odd prosody.

Since late adolescence, Mr. B repeatedly asked family members, including mother, father, and sister, whether they had witnessed him having any type of sexual intercourse with strangers. Concurrently, he started to fear that one abuser was disguised to appear as different family members to reassure him that he was not at any risk of sexual abuse (while, in fact, he thought he was at risk). Violence against his mother and sister was common, particularly when they refused to provide reassurance or, more recently, when Mr. B's concerns regarding the abuser's disguise became more intense, reaching a delusional level. However, after assaulting his mother and sister-in-law, he would generally show regret and full insight regarding the absurdity of his symptoms, arguing that they were illogical but uncontrollable. His Y-BOCS score was 39. Mr. B displayed mild depressive symptoms but did not fulfill criteria for a current major depressive disorder and did not have a history of mania. Despite a history of positive and short-lived response to lithium carbonate (prescribed by another clinician for aggressiveness), Mr. B's more recent clinical picture (dominated by OCD and Fregoli syndrome) proved to be treatment resistant to several high dose SRIs augmented by atypical antipsychotics. 


\section{DISCUSSION}

Our findings highlight an interesting phenomenon, i.e. the occurrence of DMS among patients with OCD. Although it is presently unclear whether these conditions are rare or actually underreported in OCD, our report adds to the current discussion regarding the existence of a continuum between obsessions and delusions or, alternatively, between OCD and psychotic disorders. In fact, although the rates of DMS in OCD are unknown, the distinctiveness of our series raises a range of diagnostic, etiological, and management issues, which we discuss below.

From a diagnostic point of view, we believe that our patients exhibited obsessional variants of DMS. Both of our patients displayed fluctuating levels of insight towards their OCD symptoms, a phenomenon that has been systematically described in OCD [12]. Further, while it could be argued that the co-occurrence of DMS and OCD represents a chance association, we feel there are reasons to believe in a continuum between these conditions. For instance, DMS could be conceptualized as an understandable progression of contamination (Mrs. A) and sexual/aggressive (Mr. B) obsessions facilitated by premorbid conditions, such as PPD and PDD, respectively [13]. Also, both OCD and Capgras syndrome have been characterized by failures to generate or experience "feelings of knowing" [14] or "rightness" [15], thus suggesting some sort of phenomenological overlap between these conditions. Interestingly, there are previous reports of OCD patients displaying a fear of turning into someone or 
something else or taking on unwanted characteristics [16], a phenomenon that could be considered an obsessional variant of "reverse intermetamorphosis", a rare type of DMS [17].

From an etiological perspective, it is difficult to conjecture on the mechanisms through which some patients with OCD might develop misidentification syndromes. However, in our particular cases, DMS might result from a combination of obsessive fears and preexisting cognitive bias/deficits, such as mistrustfulness (in PPD) or poor theory of mind (in PDD). It is interesting that autism (a PDD) has been associated with increased rates of PPD in OCD patients [18]. Accordingly, while paranoid tendencies might have shaped OCD symptoms in one case $[19,20]$, damaged egocentric representations of familiar persons (and its replacement by OCD-related representations) might have played a role in the other [21].

While face recognition deficits are intrinsic to the concept of DMS [3], it is also remarkable that emotional facial recognition deficits have been noted in DMS (i.e. Capgras syndrome [22] ), PDD [23], and OCD [24]. For instance, in one study, patients with high-functioning autism were found to be less accurate at processing a range of basic emotional expressions, particularly disgust, anger and surprise [25] whilst in another investigation, 33\% of OCD patients were impaired in their ability to recognize disgust expressions [24]. Therefore, one could speculate that these conditions may exist on continuum of severity or that there is an overlapping facial recognition deficit linking them. 
Our patients raise important questions in terms of therapeutic management. Although poor insight OCD has been reported to improve after conventional treatment with serotonin reuptake inhibitors (SRIs) [20, 26], our cases have shown resistance to several trials of SRIs augmented or not with antipsychotics. Accordingly, it is unclear whether DMS lead to increased treatment resistance or, in contrast, results from a chronic and refractory OCD condition. In fact, while cluster A personality disorders (including PPD) have been described as a predictor of treatment resistance in OCD [27], DMS, poor theory of mind and belligerence have led to increased "family accommodation", a phenomenon that has been associated with poorer response to pharmacotherapy and cognitivebehavioral treatment in OCD [28].

In summary, we have described what we believe is a rare complication of patients with severe and treatment resistant OCD. Future studies should be performed to identify (i) prevalence rates of Capgras syndrome and other DMS in OCD; (ii) the OCD phenotype generally associated with DMS, and (iii) what are the neurobiological mechanisms associated with DMS along different nonpsychotic psychiatric conditions. 


\section{REFERENCES}

1. Fontenelle JM, Santana Lda S, Lessa Lda R, Victoria MS, Mendlowicz MV, Fontenelle LF. [The concept of insight in patients with obsessive-compulsive disorder]. Rev Bras Psiquiatr. 2010;32(1):77-82. doi:S151644462010000100015 [pii]

2. Kozak MJ, Foa EB. Obsessions, overvalued ideas, and delusions in obsessive-compulsive disorder. Behav Res Ther. 1994;32(3):343-53. doi:00057967(94)90132-5 [pii]

3. Feinberg TE, Roane DM. Delusional misidentification. Psychiatr Clin North Am. 2005;28(3):665-83, 78-9. doi:S0193-953X(05)00044-4 [pii] 10.1016/j.psc.2005.05.002

4. Kirov G, Jones P, Lewis SW. Prevalence of delusional misidentification syndromes. Psychopathology. 1994;27(3-5):148-9.

5. Christodoulou GN, Margariti M, Kontaxakis VP, Christodoulou NG. The delusional misidentification syndromes: strange, fascinating, and instructive. Curr Psychiatry Rep. 2009;11(3):185-9.

6. Edelstyn NM, Oyebode F. A review of the phenomenology and cognitive neuropsychological origins of the Capgras syndrome. Int J Geriatr Psychiatry. 1999;14(1):48-59. doi:10.1002/(SICI)1099-1166(199901)14:1<48::AIDGPS891>3.0.CO;2-0 [pii]

7. Bourget D, Whitehurst L. Capgras syndrome: a review of the neurophysiological correlates and presenting clinical features in cases involving physical violence. Can J Psychiatry. 2004;49(11):7195.

8. Casu G, Cascella N, Maggini C. Homicide in Capgras' syndrome. Psychopathology. 1994;27(6):281-4.

9. Nilsson R, Perris C. The Capgras syndrome: a case report. Acta Psychiatr Scand Suppl. 1971;221:53-8.

10. Kimura S. Review of 106 cases with the syndrome of Capgras. Bibl Psychiatr. 1986(164):121-30.

11. Stein RM, Lipper S. An obsessional variant of capgras symptom: a case report. Bull Menninger Clin. 1988;52(1):52-7.

12. Brakoulias V, Starcevic V. The characterization of beliefs in obsessivecompulsive disorder. Psychiatr Q. 2011;82(2):151-61. doi:10.1007/s11126-0109157-8

13. Jaspers K. General Psychopathology. Maryland: JHU Press; 2007.

14. Szechtman H, Woody E. Obsessive-compulsive disorder as a disturbance of security motivation. Psychol Rev. 2004;111(1):111-27. doi:10.1037/0033295X.111.1.111

2004-10332-007 [pii]

15. Mangan B. Sensation's Ghost: The Non-Sensory "Fringe" of Consciousness. Psyche. 2001;7:18.

16. Volz C, Heyman I. Case series: transformation obsession in young people with obsessive-compulsive disorder (OCD). J Am Acad Child Adolesc Psychiatry. 2007;46(6):766-72. doi:10.1097/chi.0b013e3180465a2e S0890-8567(09)62156-0 [pii] 
17. Hanin B, Perlow M, Ben-Daniel N, Itzhaki S. Reverse intermetamorphosis-a rare misidentification phenomenon. Isr J Psychiatry Relat Sci. 1994;31(4):2969.

18. Bejerot $\mathrm{S}$, Nylander L, Lindstrom E. Autistic traits in obsessive-compulsive disorder. Nord J Psychiatry. 2001;55(3):169-76.

doi:10.1080/08039480152036047

19. Insel TR, Akiskal HS. Obsessive-compulsive disorder with psychotic features: a phenomenologic analysis. Am J Psychiatry. 1986;143(12):1527-33. 20. Alonso P, Menchon JM, Segalas C, Jaurrieta N, Jimenez-Murcia S, Cardoner $\mathrm{N}$, et al. Clinical implications of insight assessment in obsessive-compulsive disorder. Compr Psychiatry. 2008;49(3):305-12. doi:S0010-440X(07)00139-3 [pii]

10.1016/j.comppsych.2007.09.005

21. Hirstein $\mathrm{W}$. The misidentification syndromes as mindreading disorders. Cogn Neuropsychiatry. 2010;15(1):233-60. doi:917843874 [pii] $10.1080 / 13546800903414891$

22. Breen N, Caine D, Coltheart M. The role of affect and reasoning in a patient with a delusion of misidentification. Cogn Neuropsychiatry. 2002;7(2):113-37. doi:0GGFN2P84DA7R91R [pii] $10.1080 / 13546800143000203$

23. Weigelt $S$, Koldewyn K, Kanwisher N. Face identity recognition in autism spectrum disorders: A review of behavioral studies. Neurosci Biobehav Rev. 2011;36(3):1060-84. doi:S0149-7634(11)00215-6 [pii] 10.1016/j.neubiorev.2011.12.008

24. Corcoran KM, Woody SR, Tolin DF. Recognition of facial expressions in obsessive-compulsive disorder. J Anxiety Disord. 2008;22(1):56-66. doi:S08876185(07)00018-7 [pii] 10.1016/j.janxdis.2007.01.003

25. Law Smith MJ, Montagne B, Perrett DI, Gill M, Gallagher L. Detecting subtle facial emotion recognition deficits in high-functioning Autism using dynamic stimuli of varying intensities. Neuropsychologia. 2010;48(9):2777-81. doi:S0028-3932(10)00097-7 [pii] 10.1016/j.neuropsychologia.2010.03.008

26. Matsunaga H, Kiriike N, Matsui T, Oya K, Iwasaki Y, Koshimune K, et al. Obsessive-compulsive disorder with poor insight. Compr Psychiatry. 2002;43(2):150-7. doi:S0010440X02639318 [pii]

27. Hansen B, Vogel PA, Stiles TC, Gotestam KG. Influence of co-morbid generalized anxiety disorder, panic disorder and personality disorders on the outcome of cognitive behavioural treatment of obsessive-compulsive disorder. Cogn Behav Ther. 2007;36(3):145-55. doi:783091011 [pii] $10.1080 / 16506070701259374$

28. Lebowitz ER, Panza KE, Su J, Bloch MH. Family accommodation in obsessive-compulsive disorder. Expert Rev Neurother. 2012;12(2):229-38. doi:10.1586/ern.11.200 
Dr. Isabela Azeredo Melca is a mastership candidate for the Psychiatry and Mental Health Post-Graduate Program from the Institute of Psychiatry, Federal University of Rio de Janeiro (UFRJ). She got her medical degree (2007) from the Gama Filho University Medical School and completed her training in psychiatry at the Rio de Janeiro's Pontificial Catholic University (2010).

Dr. Clarissa Loureiro Rodrigues is a mastership candidate for the Psychiatry and Mental Health Post-Graduate Program from the Institute of Psychiatry, Federal University of Rio de Janeiro (UFRJ). She got her medical degree (2005) from the Souza Marques Foundation for Technical Education Medical School and is currently an officer at the Brazilian Navy.

Dr. Maria Antonia Serra-Pinheiro has been managing cases in Child and Adolescent Psychiatry and developing research focused on Attention-Deficit Hyperactivity Disorder for over 10 years. She has a Masters Degree and a PhD in Psychiatry from the Institute of Psychiatry of the Federal University of Rio de Janeiro. She got her medical degree from the Federal University of Rio de Janeiro and completed her training in Psychiatry at the Institute of Psychiatry of the Federal University of Rio de Janeiro.

Professor Christos Pantelis, is an NHMRC Senior Principal Research Fellow, Foundation Professor of Neuropsychiatry and Scientific Director of the Melbourne Neuropsychiatry Centre at The University of Melbourne and Melbourne Health. He holds an honorary Principal Research Fellow position at the Florey Neuroscience Institute and heads the Adult Mental Health Rehabilitation Unit at Sunshine Hospital. He leads a team of researchers that have been undertaking neuroimaging and neuropsychological work in schizophrenia and psychosis, and other psychiatric and neurodegenerative disorders since 1993 in Australia. His work has focused on brain structural and functional changes during the transition to psychosis. He has published over 340 papers and chapters, including papers in high-profile international psychiatry, neurology, radiology and medical journals. He published one of the first books on the neuropsychology of schizophrenia, a recently published book on "Olfaction and the Brain" and a book on "The Neuropsychology of Mental Illness".

Dr. Dennis Velakoulis is a consultant neuropsychiatrist based at the Neuropsychiatry Unit, Royal Melbourne Hospital. He is the Clinical Director of the Melbourne Neuropsychiatry Centre and Director of the Neuropsychiatry Unit. Following graduation from the University of Melbourne in Medicine, Dr Velakoulis completed a Diploma of Criminology before successfully completing his Fellowship for the RANZCP (1994) and a Masters of Medicine in Neuroscience (1998). After completing his psychiatry training Dr Velakoulis commenced as a Research Fellow in the Cognitive Neuropsychiatry Unit, Mental Health Research Institute in 1994. After a decade of working together with Professor Pantelis, they established the Melbourne Neuropsychiatry Centre in 2004. Dr Velakoulis' clinical and research work has extended across the entire spectrum of neuropsychiatry from the clinical interface between psychiatry, neurology and medicine through to the neurobiological underpinning of 
psychiatric illness, the role of neuroimaging in neuropsychiatric disorders to neuropathology and animal studies.

Dr. Mauro V. Mendlowicz is currently Associate Professor of the Department of Psychiatry and Mental Health at the Instituto de Saúde da Comunidade da Universidade Federal Fluminense in Rio de Janeiro, Brazil. He has concluded a post-doctoral fellowship at University of California, San Diego (1996-1998). Dr. Mendlowicz clinical work has focused on the management of patients with posttraumatic stress disorder (PTSD), victims of traumatic experiences and anxiety disorders. He has published over 100 articles and book chapters, including papers in peer reviewed psychiatry and psychology journals. Dr. Mendlowicz was successful in obtaining several grants from the Brazilian Council for Scientific \& Technological Development and from the Foundation for Research Support of the State of Rio de Janeiro. He is also the Co-Director of the PTSD Clinic at the Instituto de Psiquiatria da Universidade Federal do Rio de Janeiro (IPUB/UFRJ). Dr. Mendlowicz trains residents and younger psychiatrists in the care of patients with trauma-related disorders. He is also a member of several national and international societies.

Dr. Leonardo Fontenelle is currently Associate Professor of the Department of Psychiatry and Legal Medicine at the Faculdade de Medicina da Universidade Federal do Rio de Janeiro and at the Instituto de Saúde da Comunidade da Universidade Federal Fluminense in Rio de Janeiro, Brazil. There, he coordinates a team of researchers that have been undertaking studies in different areas of OCD over the last 10 years, including phenotypic features, neuroimaging, neurophysiology, neuropsychology and therapeutic management. Dr. Fontenelle has published over 100 articles and book chapters in peer reviewed journals. Dr. Fontenelle is co-Chief Investigator of the Brazilian Research Consortium in Obsessive-Compulsive Spectrum Disorders, an initiative supported by a grant from the Brazilian Council for Scientific \& Technological Development that generated one of the largest databases of patients with OCD patients in world $(n=1000)$. He is also the Director of the OCD Clinic at the Instituto de Psiquiatria da Universidade Federal do Rio de Janeiro (IPUB/UFRJ). Dr. Fontenelle clinical work has focused on the management of patients with Obsessive-Compulsive Spectrum Disorders, such as OCD, body dysmorphic disorder, and Tourette's syndrome. He trains residents and younger psychiatrists in the care of patients with Obsessive-Compulsive Spectrum Disorders. He is also a member of several national and international societies. 